\begin{tabular}{llll}
\hline $\begin{array}{l}\text { Baseline characteristics of the study } \\
\text { population. }\end{array}$ & $\begin{array}{l}\text { csDMARDs } \\
(\mathbf{n}=\mathbf{4 3})\end{array}$ & $\begin{array}{l}\text { TNFi } \\
(\mathbf{n}=64)\end{array}$ & $\begin{array}{l}\mathbf{P} \\
\text { value }\end{array}$ \\
\hline Age, median years (IQR) & $58.6(53.0,66.0)$ & $58.1(49.3,67.0)$ & 0.839 \\
Female sex & $33(76.7)$ & $54(84.4)$ & 0.321 \\
Obesity & $5(11.6)$ & $7(10.9)$ & 0.999 \\
Hypertension & $19(44.2)$ & $30(46.9)$ & 0.784 \\
Anti-hypertensive drug & $17(39.5)$ & $28(43.8)$ & 0.784 \\
Smoking status, ever & $18(42.9)$ & $30(46.9)$ & 0.684 \\
Dyslipidemia & $30(40.2)$ & $34(59.8)$ & 0.085 \\
Current statin use & $13(34.2)$ & $10(15.9)$ & 0.033 \\
Diabetes mellitus & $3(7.0)$ & $3(4.7)$ & 0.676 \\
Anti-diabetic medication & $1(2.3)$ & $1(1.5)$ & 0.999 \\
CVD risk factors, median (IQR) & $2(1,3)$ & $2(1,3)$ & 0.199 \\
RF and/or ACPA positive & $28(65.1)$ & $33(51.6)$ & 0.165 \\
Disease duration, median years (IQR) & $14.1(11.5)$ & $15.4(10.5)$ & 0.538 \\
Methotrexate & $38(88.4)$ & $52(81.3)$ & 0.192 \\
Leflunomide & $5(17.9)$ & $12(19.0)$ & 0.999 \\
Hydroxychloroquine & $9(31.0)$ & $5(7.8)$ & 0.009 \\
Prednisone > 5mg daily & $7(7.7)$ & $5(5.5)$ & 0.823 \\
NSAIDs & $6(20.7)$ & $22(34.4)$ & 0.227 \\
\hline
\end{tabular}

ACPA, anti-citrullinated peptides antibodies; csDMARDs, conventional synthetic disease-modifying anti-rheumatic drugs; IQR, interquartile range; NSAIDs, non-steroidal anti-inflammatory drugs; RF, rheumatoid factor; TNFi, tumor necrosis factor inhibitors. All data reported as absolute numbers (percentage) otherwise specified. P-value refers to Chi-squared or Fisher test for categorical variables or ANOVA for continuous variables.

Disclosure of Interests: None declared
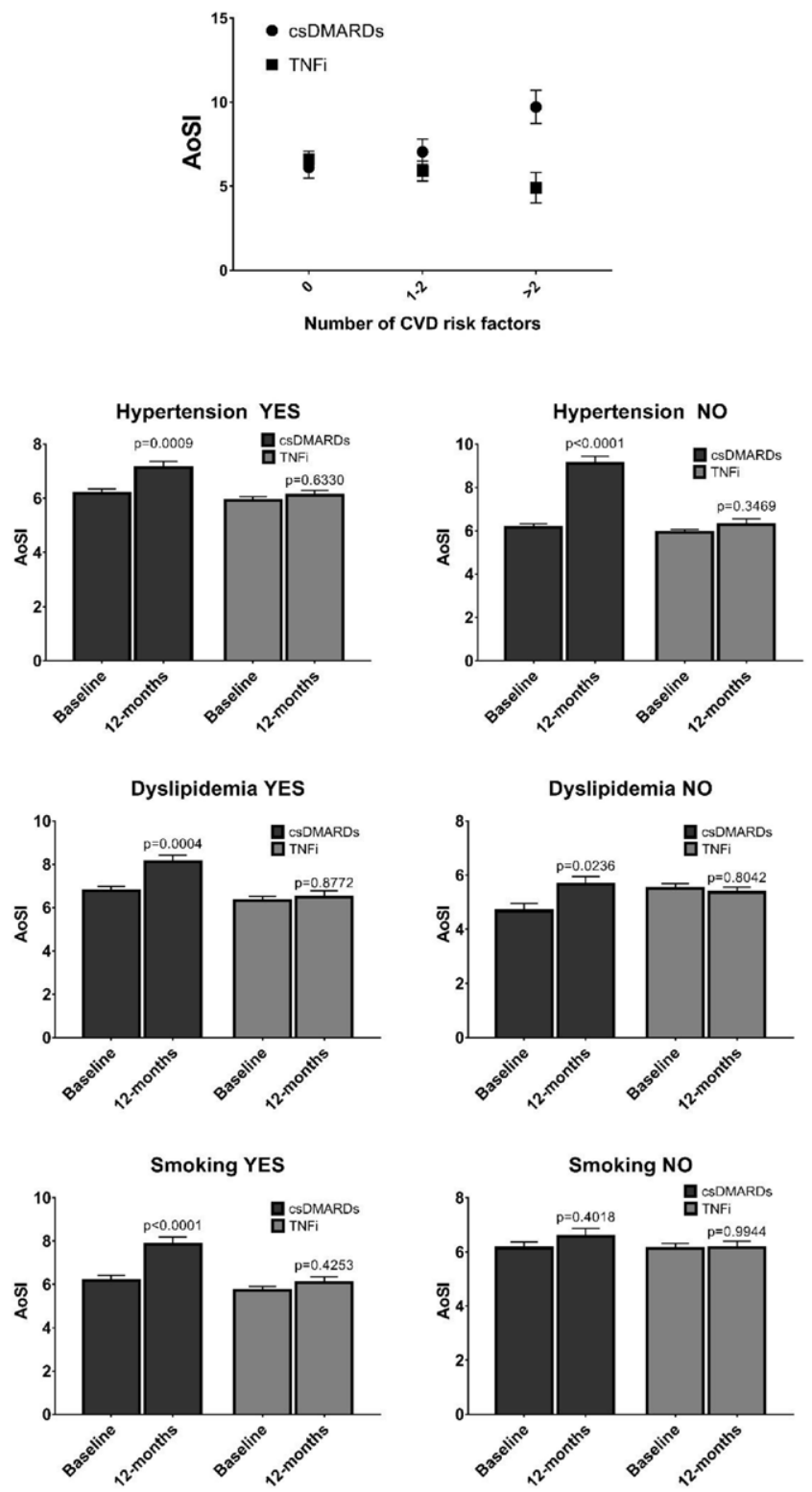

DOI: 10.1136/annrheumdis-2021-eular.404

\section{POS0219 EFFECT OF LOW-DOSE METHOTREXATE ON ESTIMATED GLOMERULAR FILTRATION RATE AND KIDNEY ADVERSE EVENTS INTHE CARDIOVASCULAR INFLAMMATION REDUCTION TRIAL}

J. Sparks ${ }^{1}$, K. Vanni ${ }^{1}$, M. Sparks ${ }^{2}$, C. Xu ${ }^{1}$, L. Santacroce ${ }^{1}$, R. Glynn ${ }^{3}$, P. Ridker ${ }^{4}$, D. Solomon'. 'Brigham and Women's Hospital, Division of Rheumatology, Boston, United States of America; ${ }^{2}$ Duke University School of Medicine, Division of Nephrology, Durham, United States of America; ${ }^{3}$ Brigham and Women's Hospital, Divisions of Cardiovascular and Preventative Medicine, Boston, United States of America; ${ }^{4}$ Brigham and Women's Hospital, Division of Preventative Medicine, Boston, United States of America

Background: Low-dose methotrexate (LD-MTX) is a common first-line treatment for systemic rheumatic diseases, and its use is contraindicated in advanced chronic kidney disease (CKD) because it is primarily excreted by the kidneys. Among patients with preserved kidney function, the safety of LD-MTX on estimated glomerular filtration rate (eGFR) and kidney adverse events (AEs) has not been established.

Objectives: To investigate the effect of LD-MTX on eGFR and kidney AEs using data from a randomized clinical trial.

Methods: We performed a secondary analysis for eGFR and kidney AEs using the randomized double-blind, placebo-controlled Cardiovascular Inflammation Reduction Trial. Adults with known cardiovascular disease and diabetes and/ or metabolic syndrome were randomly allocated to oral LD-MTX (target dose $15-20 \mathrm{mg} /$ week) or placebo. All participants took folic acid $1 \mathrm{mg}$ six days/week. Exclusion criteria included systemic inflammatory disease and creatinine clearance $<40 \mathrm{~mL} / \mathrm{min}$ (by Cockcroft-Gault). eGFR was calculated using the CKD-EPI formula. Clinical kidney AEs were blindly adjudicated. The least-squares mean change of eGFR from baseline was calculated at each study visit; the difference in eGFR slopes between LD-MTX and placebo was compared using a modified intention-to-treat approach. We also compared rates of kidney AEs for LD-MTX versus placebo using Cox proportional hazards models.

Results: A total of 2,391 subjects were randomized to LD-MTX and 2,395 to placebo. At baseline, mean age was 66 years, $19 \%$ were female, mean eGFR was $80.0 \mathrm{~mL} / \mathrm{min} / 1.73 \mathrm{~m}^{2}$, and $18 \%$ had stage 3 CKD or worse. Median follow-up duration was 23 months, and median LD-MTX dose was $16 \mathrm{mg} /$ week. Those randomized to LD-MTX had less decline in eGFR over the entire follow-up compared to placebo (slope difference 1.12, 95\% $\mathrm{Cl} 0.59-1.65, p<0.001$, Figure 1). Those with CKD stage 3 or worse on LD-MTX saw less eGFR decline than those with CKD stage 2 or better (slope difference among CKD stage 3 or worse: $2.46,95 \% \mathrm{Cl} 1.10-3.82, p<0.001 ; p$ for interaction 0.02). The LD-MTX group had higher eGFR than placebo over the first 24 months of study follow-up ( $p<0.05$ at each visit). On safety laboratory monitoring, there were 159 acute kidney injury AEs in the LD-MTX group and 187 in the placebo group ( $\mathrm{HR} 0.83,95 \% \mathrm{Cl} 0.67-1.02$, Table 1). There were 37 clinical kidney AEs in the LD-MTX group and 42 in the placebo group $(0.87,95 \% \mathrm{Cl} 0.56-1.36)$. One subject began dialysis in the LD-MTX group compared to 3 in the placebo group.

Conclusion: These results demonstrate the kidney safety of LD-MTX among patients without advanced CKD at baseline. We observed a possible beneficial effect of LD-MTX on preserving kidney function, suggesting that inflammation may be involved in the pathogenesis of CKD in this population.

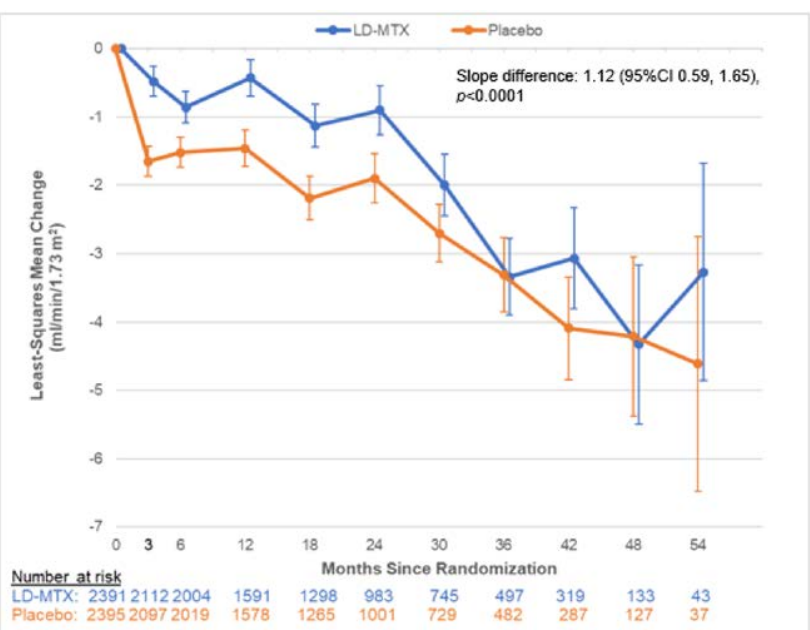

Figure. Least-squares mean change of estimated glomerular filtration rate (eGFR) from baseline to each follow-up visit according to random assignment of low-dose methotrexate (LD-MTX) or placebo in the Cardiovascular Inflammatory Reduction Trial $(n=4,786)$. eGFR was calculated using the CKD-EPI equation. A slope difference significantly above 0 denotes less decline in eGFR for the LD-MTX group. 
Table 1. Rates and hazard ratios for kidney adverse events per random assignment of low-dose methotrexate or placebo in the Cardiovascular Inflammation Reduction Trial $(n=4,786)$.

\begin{tabular}{|c|c|c|c|c|c|}
\hline & \multicolumn{4}{|c|}{$\begin{array}{l}\text { Low-dose methotrexate Placebo }(n=2,395) \\
\begin{array}{ll}(n=2,391) & \text { (reference) }\end{array}\end{array}$} & \multirow[b]{2}{*}{$\mathrm{HR}(95 \% \mathrm{Cl})$} \\
\hline & Events & $\begin{array}{l}\text { Rate per } 100 \\
\text { person-years } \\
(95 \% \mathrm{Cl})\end{array}$ & Events & $\begin{array}{l}\text { Rate per } 100 \\
\text { person-years } \\
(95 \% \mathrm{Cl})\end{array}$ & \\
\hline \multicolumn{6}{|c|}{$\overline{\text { SCr collected at safety visits }}$} \\
\hline Any event ${ }^{*}$ & 159 & $3.42(2.93,3.98)$ & 187 & $4.06(3.53,4.67)$ & $0.83(0.67,1.02)$ \\
\hline $\begin{array}{l}\text { Mild (SCr 1.5-1.9x } \\
\text { baseline) }\end{array}$ & 154 & $3.47(2.97,4.06)$ & 177 & 4.06 & $0.85(0$. \\
\hline $\begin{array}{l}\text { Moderate (SCr 2-2.9 } \\
\text { baseline) }\end{array}$ & $\times 19$ & $0.41(0.26,0.64)$ & 24 & $0.52(0.35,0.78)$ & $0.78(0.43,1.43)$ \\
\hline $\begin{array}{l}\text { Severe }(\mathrm{SCr} \geq 3 \mathrm{x} \\
\text { baseline) }\end{array}$ & 2 & $0.04(0.01,0.17)$ & 5 & $0.11(0.05,0.26)$ & $0.40(0.08,2.04)$ \\
\hline \multicolumn{6}{|c|}{ Adjudicated clinical kidney adverse events } \\
\hline Any event ${ }^{\star}$ & 37 & $0.80(0.58,1.11)$ & 42 & $0.92(0.68,1.24)$ & $0.87(0.56,1.36)$ \\
\hline Mild & 24 & $0.52(0.35,0.77)$ & 25 & $0.55(0.37,0.81)$ & $0.95(0.55,1.67)$ \\
\hline Moderate & 11 & $0.24(0.13,0.43)$ & 11 & $0.24(0.13,0.43)$ & $1.00(0.43,2.29)$ \\
\hline Severe & 4 & $0.09(0.03,0.23)$ & 8 & $0.17(0.09,0.35)$ & $0.50(0.15,1.64)$ \\
\hline New dialysis & 1 & $0.02(0.00,0.15)$ & & $0.17(0.09,0.35)$ & $0.34(0.04,3.17)$ \\
\hline
\end{tabular}

${ }^{*}$ Acute kidney injury presence and severity was defined by KDIGO (Kidney Disease: Improving Global Outcomes) classification.

$\mathrm{Cl}$, confidence interval; $\mathrm{HR}$, hazard ratio; $\mathrm{SCr}$, serum creatinine.

Disclosure of Interests: Jeffrey Sparks Consultant of: Dr. J Sparks has performed consultancy for Bristol-Myers Squibb, Gilead, Inova Diagnostics, Optum, and Pfizer unrelated to this work., Grant/research support from: Dr. J Sparks has received research support from Bristol-Myers Squibb., Kathleen Vanni: None declared, Matthew Sparks: None declared, Chang Xu: None declared, Leah Santacroce: None declared, Robert Glynn Grant/research support from: Dr. Glynn has received grant support unrelated to the present research from AstraZeneca, Kowa, Pfizer, and Novartis., Paul Ridker Consultant of: Dr. Ridker has served as a consultant to Corvidia, Inflazome, and CiviBioPharm., Grant/research support from: Dr. Ridker receives research support unrelated to the present study from Kowa, Novartis, and Amarin., Daniel Solomon Grant/research support from: Dr. Solomon receives research support unrelated to the present study from Abbvie, Amgen, Corrona, Genentech, Janssen, and Pfizer. DOI: 10.1136/annrheumdis-2021-eular.1627

\section{Rheumatoid arthritis - non biologic treatment and small molecules - PART 2}

\section{POS0220 INTEGRATED SAFETY PROFILE OF UPADACITINIB WITH UP TO 4.5 YEARS OF EXPOSURE IN PATIENTS WITH RHEUMATOID ARTHRITIS}

S. B. Cohen ${ }^{1}$, R. Van Vollenhoven ${ }^{2}$, J. R. Curtis ${ }^{3}$, L. Calabrese ${ }^{4}$, C. Zerbini ${ }^{5}$, Y. Tanaka ${ }^{6}$, L. Bessette ${ }^{7}$, C. Richez ${ }^{8}$, I. Lagunes-Galindo ${ }^{9}$, J. Liu ${ }^{9}$, H. Camp ${ }^{9}$, Y. Song ${ }^{9}$, S. Anyanwu ${ }^{9}$, G. R. Burmester ${ }^{10} .{ }^{1}$ Metroplex Clinical Research Center, Rheumatology, Dallas, Texas, United States of America; ${ }^{2}$ Amsterdam Rheumatology and Immunology Center, Rheumatology and Immunology, Amsterdam,

Netherlands; ${ }^{3}$ University of Alabama at Birmingham, Rheumatology, Birmingham, Alabama, United States of America; ${ }^{4}$ Cleveland Clinic, Rheumatology, Cleveland, Ohio, United States of America; ${ }^{5}$ Centro Paulista de Investigacao Clínica,

Rheumatology, São Paulo, Brazil; ' ${ }^{6}$ University of Occupational and Environmental Health, Rheumatology, Kitakyushu, Japan; ' Laval University, Rheumatology, Quebec City, Quebec, Canada; ${ }^{8}$ Université de Bordeaux, Rheumatology, Bordeaux, France; ${ }^{9}$ AbbVie Inc., Immunology, North Chicago, United States of America; ${ }^{10}$ Charité University Medicine, Rheumatology, Berlin, Germany

Background: The safety and efficacy of the oral Janus kinase inhibitor upadacitinib (UPA) has been evaluated across a spectrum of patients with rheumatoid arthritis (RA) in the phase 3 SELECT clinical program. ${ }^{1-6}$

Objectives: To describe the long-term integrated safety profile of UPA relative to active comparators (cutoff date: June 30,2020 ) in patients with RA treated in the SELECT clinical program.

Methods: This analysis included updated data from 6 randomized controlled UPA RA trials. ${ }^{1-6}$ Treatment-emergent adverse events (TEAEs; onset after first dose and $\leq 30$ days after last dose of study drug or $\leq 70$ days for adalimumab [ADA]) including AEs of special interest were summarized as follows: pooled UPA $15 \mathrm{mg}$ once daily (QD; UPA 15,6 trials); pooled UPA $30 \mathrm{mg}$ QD (UPA30, 4 trials); methotrexate (MTX, 1 trial), and ADA (1 trial). TEAEs were reported as exposure-adjusted adverse event rates (EAERs; events/100 patient-years [E/100 $\mathrm{PY}]$ ), which included both incident and recurrent events.

Results: 4413 patients (UPA15, $n=3209$; UPA30, $n=1204$ ) received $\geq 1$ dose of UPA, providing 10,115.4 PY of exposure. EAERs for AEs, serious AEs (SAEs), and AEs leading to discontinuation were similar for UPA15, MTX, and ADA; rates for UPA30 were numerically higher than UPA15 (Table 1). The most common AEs were upper respiratory tract infection, nasopharyngitis, and urinary tract infection for both UPA doses, and for UPA30 only, increased creatine phosphokinase (CPK). Pneumonia was the most common SAE for both UPA15 and UPA30. Serious infection rates were similar for UPA15, MTX, and ADA but higher for UPA30 (Figure 1). Rates of herpes zoster ( $\mathrm{HZ}$ ) were higher for both UPA groups (dose-dependent) vs MTX and ADA. Most $\mathrm{HZ}$ cases with UPA were non-serious (94\%) and involved a single dermatome (74\%). CPK elevations, which were mostly asymptomatic, were more common for both UPA groups (dose-dependent) vs MTX and ADA. EAERs of adjudicated gastrointestinal perforations were $<0.1$ and $0.2 \mathrm{E} / 100$ PY for UPA15 and UPA30, respectively. Rates of non-melanoma skin cancer (due in part to more recurrent events with UPA30), anemia, and neutropenia were higher with UPA30 vs other treatment groups. Events of anemia and neutropenia were generally mild/moderate and treatment discontinuation due to these events was uncommon $(<0.4 \%)$. Rates of other AEs of special interest, including major adverse cardiovascular and venous thromboembolic events, were broadly similar across treatment groups. The rate of deaths in UPA-treated patients with RA was not higher than expected for the general population (standardized mortality ratio [95\% confidence interval (Cl)]: UPA15, $0.43[0.29,0.63]$; UPA30, $0.68[0.40,1.08]$ ). Conclusion: The updated safety profile of UPA with up to 4.5 years of exposure in patients with RA was comparable to previous analyses, ${ }^{7}$ with no new safety signals reported. With the exception of $\mathrm{HZ}$ and elevated $\mathrm{CPK}$, the safety profile of UPA15, the approved dose for RA, was similar to that observed for ADA. REFERENCES:

[1] Burmester GR, et al. Lancet 2018;391:2503-12;

[2] Smolen JS, et al. Lancet 2019;393:2303-11;

[3] Fleischmann R, et al. Arthritis Rheumatol 2019;71:1788-800;

[4] Genovese MC, et al. Lancet 2018;391:2513-24;

[5] van Vollenhoven R, et al. Arthritis Rheumatol 2020;72:1607-20;

[6] Rubbert-Roth A, et al. N Engl J Med 2020;383:1511-21;

[7] Cohen SB, et al. Ann Rheum Dis 2020;79(Suppl 1):319-20.

Table 1. TEAEs in patients treated with UPA, MTX, and ADA

\begin{tabular}{|c|c|c|c|c|}
\hline & UPA $15 \mathrm{mg}$ QD & UPA $30 \mathrm{mg}$ QD & ADA $40 \mathrm{mg}$ EOW & MTX \\
\hline$n$ & 3209 & 1204 & 579 & 314 \\
\hline \multicolumn{5}{|l|}{ Exposure } \\
\hline Total, PY & 7023.8 & 3091.6 & 1051.8 & 637.4 \\
\hline Mean (SD), weeks & $114(64)$ & $134(66)$ & $95(70)$ & $106(67)$ \\
\hline $\begin{array}{l}\text { Median (range), weeks } \\
\text { E/100 PY }(95 \% \mathrm{Cl})\end{array}$ & s $136(0,232)$ & $160(0,231)$ & $118(2,231)$ & $144(1,221)$ \\
\hline Any $\mathrm{AE}$ & $\begin{array}{l}230.7 \text { (227.2, } \\
234.3)\end{array}$ & $\begin{array}{l}283.6(277.7, \\
289.6)\end{array}$ & $\begin{array}{l}216.6(207.8, \\
225.7)\end{array}$ & $\begin{array}{l}227.8(216.2, \\
239.8)\end{array}$ \\
\hline Any SAE & $13.0(12.2,13.9)$ & $18.8(17.3,20.4)$ & $13.3(11.2,15.7)$ & $10.4(8.0,13.2)$ \\
\hline $\begin{array}{l}\text { Any AE leading to } \\
\text { discontinuation of } \\
\text { study drug }\end{array}$ & $5.6(5.0,6.1)$ & $8.5(7.5,9.6)$ & $6.8(5.3,8.5)$ & $6.3(4.5,8.5)$ \\
\hline Deaths ${ }^{a}$ & $0.4(0.3,0.6)$ & $0.6(0.3,0.9)$ & $0.9(0.4,1.6)$ & $0.5(0.1,1.4)$ \\
\hline
\end{tabular}

${ }^{\mathrm{a} B}$ Both treatment and non-treatment-emergent deathsEOW, every other week

Acknowledgements: AbbVie funded this study; contributed to its design; participated in data collection, analysis, and interpretation of the data; and participated in the writing, review, and approval of the abstract. No honoraria or payments were made for authorship. Medical writing support was provided by Hilary Wong $\mathrm{PhD}$, of 2 the Nth (Cheshire, UK), and was funded by AbbVie.

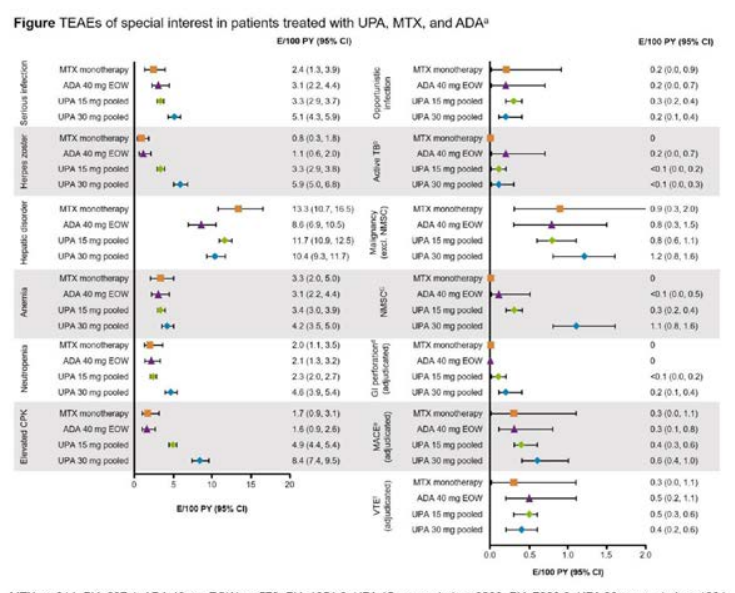
MTX; $n=314$, PY=637.4; ADA $40 \mathrm{mg}$ EOW: $n=579$, PY=1051.8; UPA $15 \mathrm{mg}$ pooled: $n=3209$, PY=7023.8; UPA $30 \mathrm{mg}$ pooled: $n=1204$.
PY=3091.6

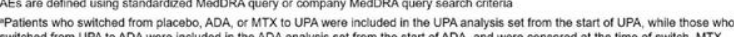
swiched from UPA to ADA were included in the ADA analysis set from the start of ADA. and were censocrec at the time of switch. MTX

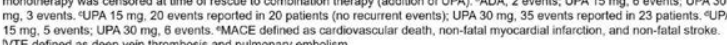
ADA, adalimumab; Cl, confidence interval: CPK, creatine phosphokinase: E1100 PY, events per 100 patient-years, EOW, every other
week; GI, gastrointestinal; MACE, major adverse cardiovascular event: MecDRA, Medical Dictionary for Regulatory Activites; MTX,

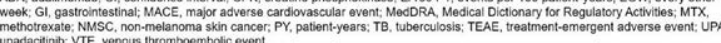

